Article

\title{
How Can E-Commerce Businesses Implement Discount Strategies through Social Media?
}

\author{
Junjie Lv ${ }^{1, *}$, Zichen Wang ${ }^{1}$, Yuqing Huang ${ }^{2}$, Tong Wang ${ }^{1}$ and Yuanzhuo Wang ${ }^{3}$ \\ 1 School of E-Business and Logistics, Beijing Technology and Business University, Beijing 100048, China; \\ marshp838@gmail.com (Z.W.); wang.tong7@fesco.com.cn (T.W.) \\ 2 College of Liberal Arts and Sciences, Northern Illinois University, DeKalb, IL 60115, USA; yhuang4@niu.edu \\ 3 Institute of Computing Technology, Chinese Academy of Sciences, Beijing 100049, China; \\ wangyuanzhuo@ict.ac.cn \\ * Correspondence: lvjj@th.btbu.edu.cn; Tel.: +86-138-1189-6079
}

Received: 15 August 2020; Accepted: 7 September 2020; Published: 10 September 2020

check for updates

\begin{abstract}
In the context of the global economic downturn caused by COVID-19, e-commerce has become the first choice for people to shop. Many merchants choose to launch promotion activities through some social media platforms. Price discounts can dramatically increase sales volume in social e-commerce due to the interaction of online consumers. It is urgent for e-commerce merchants to learn rules about discount information dissemination in social media, so as to formulate reasonable discount strategies and achieve sustainable business. This paper constructs an evolutionary game model for e-commerce platforms and merchants when they implement promotion strategies through social media, investigates discount information dissemination among consumers under multiple situations by introducing price discount parameters, and further discusses the influence mechanism of discount size and platform reputation on consumers' purchase behavior. Results show that in low-reputation e-commerce platforms, the price discount is the main motivation to purchase. Consumers' preference for the high discount is weakened by the increase in platforms' reputation. Discounts should be set according to the different reputations. Businesses in a high-reputation environment are relatively more profitable. E-commerce businesses should work together, apply reasonable pricing, and improve their quality to create a green and healthy shopping environment, in order to get benefits and sustainable development.
\end{abstract}

Keywords: purchase behavior; information dissemination; evolutionary game; behavior modeling; price discount; social e-commerce; e-commerce reputation

\section{Introduction}

The spread of COVID-19 is having a severe negative impact on the global economy. As for China, in the first quarter of 2020, GDP fell by $6.8 \%$ and retail sales of consumer goods by $19.0 \%$ year-on-year-the steepest drop in recent years. Countries have taken measures to stimulate consumption and revive their economies, such as China's government subsidies for the public in the form of online coupons [1]. E-commerce has become the first choice for people to shop during the epidemic because of its contactless shopping process. The existing problems in e-commerce have also become more prominent-how to get more people to know the product? Many merchants choose to launch promotional activities through some social media platforms, encouraging consumers to forward information and invite online friends, so as to achieve the goal of spreading brands and promoting sales. Promotional information is not simply transmitted by sellers to consumers, but is disseminated more among consumers [2,3]. The various informational and social characteristics of social environments, such as being exposed to other consumers' opinions or choices, or even just to friends' lives through social media, can motivate their purchase 
intention [4-6]. Consumers always come together in social groups, which may exert greater social influence on members and shape their cognition and behavior $[7,8]$. Social media enable companies to deal with customers more cost-effectively and efficiently than traditional media, they can save costs for enterprises in achieving sustainable development [9-11]. Pinduoduo, one of the most famous e-commerce platforms in China, launched a "Billions Subsidies Promotion" to discount more than 23,000 products in 2019, and carried it out publicity on social platforms such as Sina Weibo and TikTok. This directly led to a 20-fold increase in sales of the iPhone series compared to the same period last year [12].

It is a confusing issue for businesses when trying to develop a reasonable promotional strategy through social media. In practical terms, consumers' online friendships are constantly changing, which has a significant influence on consumer behavior [13,14]. E-commerce platforms' reputation will also affect the promotion effect [15]. For example, in lower reputation e-commerce platforms, platforms do not strictly supervise themselves, for example regarding inflated prices and disorderly discounts, consumers' purchase intention will also be reduced. Therefore, in the context of the COVID-19 epidemic, exploring discount information dissemination rules in social media and accurately predicting purchase rates in e-commerce is necessary for the sustainable operation of enterprises. In theoretical terms, platform enterprises are the owners, providers and operators of the e-commerce ecosystem, and often play the dominant role. They are responsible for maintaining the order of the trading market, making trading rules to attract more suppliers and consumers to participate in the e-commerce system [16]. Wang et al. applied customer equity drivers (value equity, brand equity, and relationship equity) to prove that SNS (social network site) marketing activities improve the overall customer outcome, that is, SNS marketing activities are a sustainable competitive advantage [17]. Some scholars have also discussed how to strengthen the supervision of platforms and improve the communication efficiency of consumers [18-20]. However, how should e-commerce platforms implement their discount strategies in social media within the framework of sustainability? There is no specific and feasible plan. A knowledge gap could be addressed by this research.

The evolutionary game can describe well the dynamic evolution process of information dissemination in complex social networks [21-23], and it has also been extended to study purchase behavior [24]. In this paper, price discount parameters are introduced, and an evolutionary game model is established which describes social media promotion strategies in e-commerce. This paper investigates the dynamic propagation of price discount information spreading between consumers, exploring the influence mechanism of consumers' purchase behavior. Suggestions are made on developing the sustainable price discount strategy for merchants and platforms.

\section{Literature Review}

Scholars have conducted many studies on social e-commerce, which is divided into two categories: one is based on e-commerce, and the other is based on the social network [8,25]. Syedahmad and Murphy argued that social networking as a marketing tool could help sellers save marketing costs, improve buyers' purchasing experience, and achieve a win-win situation for both buyers and sellers [26]. Thus, the enterprise ecosystem of an e-commerce platform with healthy and sustainable development can be constructed. At present, the case of the integration of internationally renowned e-commerce and social networking platform enterprises is shown in Table 1. 
Table 1. The integration of e-commerce and social networking platforms.

\begin{tabular}{|c|c|c|}
\hline Industry & Platform & Measure \\
\hline E-commerce & Taobao & $\begin{array}{l}\text { The platform is equipped with an online social community, } \\
\text { which allows users to post shopping experiences to their online friends. }\end{array}$ \\
\hline E-commerce & Pinduoduo & $\begin{array}{l}\text { Users can invite online friends to click on product links to help them } \\
\text { bargain or buy together, and group purchases can get extra discounts. }\end{array}$ \\
\hline E-commerce & Amazon & $\begin{array}{c}\text { It has launched "Amazon Posts" to browse and find products on } \\
\text { Amazon's platform. It functions like social media tweets, allowing each } \\
\text { brand to post a series of posts. }\end{array}$ \\
\hline Social media & TikTok & $\begin{array}{l}\text { Internet celebrities with a large number of followers can sell goods live } \\
\text { on the platform and add product links in videos or live broadcasts. }\end{array}$ \\
\hline Social media & WeChat & $\begin{array}{l}\text { It cooperates with multiple e-commerce platforms. Sharing the } \\
\text { shopping page with WeChat friends can get users discounts, and it adds } \\
\text { the shopping platform "Jingdong" entrance on the home page. }\end{array}$ \\
\hline Social media & Facebook & $\begin{array}{l}\text { It has launched the Facebook Shop app, as well as Facebook Live } \\
\text { Shopping, where companies can set up Live experiences for specific } \\
\text { products and provide links for viewers to buy directly from videos. }\end{array}$ \\
\hline Social media & Instagram & $\begin{array}{c}\text { With the 'Checkout' feature, people can buy directly from Instagram } \\
\text { instead of going directly to the retailer's website. }\end{array}$ \\
\hline
\end{tabular}

In the study on e-commerce group buying, scholars analyzed various factors affecting buying behavior. Xie and Lee investigated the effects of exposures to earned and owned social media activities and their interaction on brand purchase in a two-stage decision model [27]. Erkan and Evans examined the influence of conversations between online friends in social media on consumers' purchase intentions based on the integration of the information adoption model [28]. Scholars collected actual data from e-commerce platforms to conduct empirical studies. Kwahk and Kim posited social interaction ties and social media commitment as key elements when exploring the effects of social media on consumers' purchase decisions [29]. They tested the hypotheses based on survey data collected from Taobao, the largest e-commerce site in China. The above explored the influence factors of social media on purchasing behavior qualitatively. Weng developed a theory of online buyer behavior to explain the process buyers go through while making an online purchase, which proved the importance of perceived value to e-purchase intention [30]. Subsequent research explored the grouping buying from the perspective of technology acceptance [31]. However, there is a lack of consideration of the specific role of the price discount.

In online purchasing, a discount on the price had a significant impact on the sales volume of the goods in promotional activities [32]. See Table 2 for the current research on discount. Social media is widely used to promote viral marketing through its powerful connection and interpersonal relationship-building capabilities. Lots of studies examined the positive impact of social media on increasing brand exposure; Kim examined the effect of social sharing on sales, such as Facebook "likes" and Twitter "tweets" by analyzing actual data. Results showed that not all social referrals are meaningful in terms of increasing sales [33]. Zhou et al. studied how the discount ratio contained in the promotional information pushed by social media to users affects the behavior of users clicking on the information [34], trying to find out the influence of discount on information forwarding in social media. These studies conducted qualitative research on the price discount from the influence factors, but did not quantify the influence factors into the specific formula. 
Table 2. Current research on price discount.

\begin{tabular}{cc}
\hline \multicolumn{1}{c}{ Research Contents } & Author \\
\hline The influence of different ways of price discount & Estelami C [35], Mariola and Delgado [36], Teng [37] \\
\hline The influence of discount frequency & Gupta [38], Chen and Cheng [39] \\
\hline $\begin{array}{c}\text { The influence of discount restrictions (time limit, } \\
\text { quantity limit) }\end{array}$ & $\begin{array}{c}\text { Corso and Lobler [40], Francesca Greco [41], Huiling } \\
\text { and Stephanie [42], Hélène Cristini [43] }\end{array}$ \\
\hline $\begin{array}{c}\text { Influence of quality and scope of discount } \\
\text { information }\end{array}$ & Khouja and Liu [44], Gong et al. [45] \\
\hline $\begin{array}{c}\text { Influence of price discount magnitude } \\
\text { Kearden and Hardesty (2003) [46], Sheehan et al. } \\
\text { (2019) [47] }\end{array}$ \\
\hline
\end{tabular}

Besides, Carlson and Kukar verified the effect of consumers on discount credibility and provided ideas for the establishment of the platform reputation update [48]. Platforms' reputation and price promotion are particularly important for the sustainable development of e-commerce enterprises. When consumers notice that a company sells products or brands with positive word of mouth and also provides information and knowledge through SNSs, which offer convenience for customers, they build a positive image of the products or brands that the company offers and these positive reputations eventually lead them to trust the company [49]. This reputation-based trust is the resource that generates sustainable competitive advantage [50,51]. Consumer trust in a product, brand information and knowledge made available through social networks can reinforce future purchase intention and provide a sustainable competitive advantage for traditional markets [52]. However, the studies [48-52] did not take into account the amplifying effect of social media when reputation and promotional messages are disseminated between consumers.

Scholars built models to find the internal mechanism of information transmission in social media. Qiu et al. presented a game model to simulate the processes of information dissemination at different stages and introduced knowledge, beliefs, memories, and reputation into the benefit function to study the influence of individual characteristics on their information dissemination behavior [53]. The evolutionary game theory used in this paper is an effective method to describe the dynamic changes of network structure. Li et al. constructed an evolutionary game model between opinion leaders and netizens on the condition that participants are not completely rational [54]. Yu et al. proposed a social evolutionary game model and attempted to interpret human impacts on information dissemination. In his model, the reputation mechanism is introduced to change the network structure [21,22]. Wang et al. provided several analysis methods for modeling of network group behaviors and stochastic evolutionary games [23]. This gives a better direction for exploring the updating mechanism of group behavior evolution.

The previous studies also used real data to prove that the social evolutionary game model applied in this paper fits with the real scene in information dissemination [55,56]. Social behavior and purchasing behavior can be organically combined. Akar and Dalgic integrated the social network theory and the theory of planned behavior to analyze online consumers' purchase intentions and to investigate their structural positions by analyzing their friendships in social networks [57]. Lv et al. extended the social evolutionary game model to simulate multiple complex social e-commerce networks, linking purchase decisions to information forwarding, and tried to explore the internal relation between users' information dissemination in social media and online shopping behavior [24]. At present, there are few types of research on the diffusion mechanism of price discount information of e-commerce in social media. 


\section{Evolutionary Game Model of Social Media Promotion Strategies in E-Commerce}

\subsection{Model Hypothesis}

\subsubsection{Purchase Behavior in E-Commerce}

Consumers would only purchase products if they had the intention to do so first. Therefore, in order to accurately predict consumers' purchase behavior, it is necessary to conduct in-depth research on consumers' purchase intentions [58]. Purchase intention is the possibility that consumers are willing to buy a product [59]. According to the transaction value theory, consumers will comprehensively consider the gains and losses brought by specific purchase behaviors, and take the trade-offs, namely perceived value, as an important antecedent to affect purchase intention [60].

$\mathrm{Fu}$ divided the factors that influence consumers' purchase intention from the following two dimensions. First, the individual factors, mainly including consumers' needs and motivations, perception, attitudes, personality psychology, self-knowledge, lifestyle, and other factors; second, the individual aspect. Second, the environmental factors mainly include culture, social class, reference group, consumption situation, and so on [61]. In this paper, the influence of purchase behavior is divided into environmental factors and individual factors (See Figure 1).

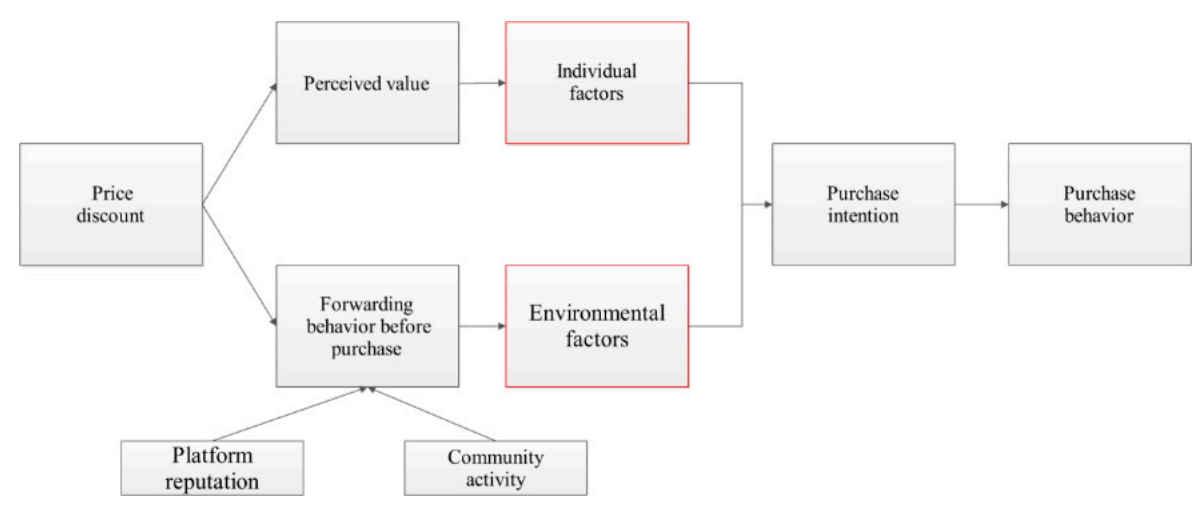

Figure 1. Diagram of influencing factors of purchase behavior.

As is shown in Figure 1, for each individual, the behavior of their online friends in social media constitutes their shopping environment. Consumers can see the shopping information forwarded by their friends and the herd mentality affects them deeply. In addition, the reputation of e-commerce platforms and the activity of social e-commerce communities can influence information dissemination by changing the relationship between their friends [21]. Besides environmental factors, there are also individual factors that come from consumers' own judgment of the discount. The results of empirical studies show that consumers' judgment on the perceived value of commodity transactions before purchasing directly affects their purchase intention [62,63].

\subsubsection{Information Dissemination in Social Media}

In social media platforms, all users have their own social group of friends who are "online neighbors" with similar interests and preferences. In online shopping social groups, users can quickly obtain product information, they pay more attention to the content generated by friends, and are more willing to share and forward a friend's information $[7,8]$. Users get product information from their shopping communities, which are forwarded by online neighbors or published by merchants. In the initial stage of information dissemination, some active users will begin to focus on the forwarded information and forward the information again to their friends, but the dissemination of this information is still limited to their friends' relationships [21,22]. This information dissemination process is shown in Figure 2. 


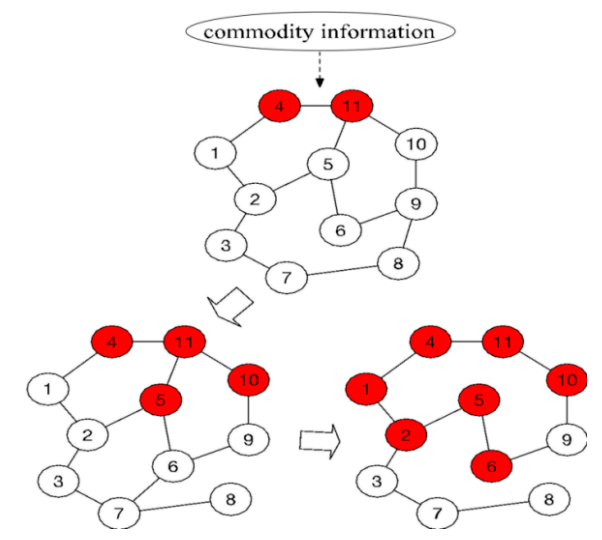

Figure 2. Schematic diagrams of discount information dissemination.

As shown in Figure 2, in the initial state, price discount information begins to spread. The red circle represents the users who have received the product information. User 4 and user 11 are the first to get the discount information. They can choose whether to forward the message or not, and the decision is made according to the temptation of price discount messages and the herd mentality. After making decisions, their neighbors (user 1, user 5, and user 10) have a certain probability of seeing the forwarded information and deciding whether to forward or not, while other users remain unchanged. At the same time, users can also choose to disconnect from their friends or establish a new friendship. By analogy, it eventually develops into a relatively stable state. Only the red individuals who receive the discount information have the ability to make a purchase decision [24]. Therefore, it is of great significance to explore the mechanism of information dissemination for merchants to promote sales and sustainable development.

\subsubsection{User Strategies in Social Media}

The individuals in the model are e-commerce users and have their own social media accounts. Users with similar interests gather in an online social media community and share information. On the social media platform, a high discount may stimulate individuals' desire to share information with their friends. Each individual has two alternative strategies: Cooperate $C\left(s=[1,0]^{\mathrm{T}}\right)$ or defect $D\left(s=[0,1]^{\mathrm{T}}\right)$. Cooperate means participating in information dissemination and interacting with online friends. Defect means there is no participation in the information dissemination. Due to the limitation of network structure and an individual's ability to obtain information, individuals can obtain information only limited to a two-step distance. That is, individuals can find information shared by their neighbors and their neighbors' neighbors with a certain probability. Individuals who receive promotional information have the ability to purchase goods, which largely depends on the price discount and the behavior of their neighbors.

The relationship between individuals on social media is set as a directed graph. Individual $i$ has two kinds of neighbors: OUT-neighbors and IN-neighbors. If individual $j$ focuses on individual $i$, then the direction of edge $e_{i j}$ between individual $i$ and $j$ can be described as $j \rightarrow i$. In this case, individual $j$ is the IN-neighbor of individual $i$, and individual $i$ is the OUT-neighbor of individual $j . N_{i}$ and $N_{i}{ }^{I}$ are the IN-neighbor set and the OUT-neighbor set of individual $i$, respectively. $d_{i}{ }^{I}$ and $d_{i}$ are the in-degree and out-degree of individual $i$, used to represent the total number of individual $i$ 's IN-neighbors and OUT-neighbors, respectively. The degree of individual $i$ is the sum of its in-degree and out-degree, called $d_{i}$.

\subsection{Modeling}

The evolutionary game model of social media and e-commerce users can be represented by a group set $G=(V, E, I, U, R, B, P, p c)$ with a number of relevant attributes. The explanations for each part are as follows: 
- $\quad V=\left(V_{1}, V_{2}, V_{3} \ldots, V_{n}\right)$ is the set of agents.

- $E=\left(e_{1}, e_{2}, e_{3} \ldots, e_{n}\right)$ is the set of partnerships among the agents.

- $\quad I$ is the set of interactions performed by the agents based on their corresponding strategies.

- $U$ is the set of utility functions of the agents. The utility is the short-term concern of social e-commerce users. Participants improve their own utility by imitating the strategies adopted by other successful participants. Each participant's utility is the cumulative payoffs obtained from their opponents, formulated as

$$
u_{i}=\sum_{j \in N_{i}} S_{i}^{T} M S_{j}
$$

where $N_{i}$ is the set of $i$ 's neighbors, $S_{i}$ and $S_{j}$ are the strategies adopted by $i$ and $j$, respectively. $M$ is the benefits matrix.

- $\quad R$ is the set of reputation functions of the agents. The reputation of individual $i$ refers to other people's history of impression on them due to their behavioral strategy. The more cooperative behavior is, the higher the reputation value becomes. In this model, every social e-commerce user will pay attention to the reputation for the long term; at the same time, users will adjust the relationship according to the reputation.

- $\quad B$ is the purchase intention function. Purchase intention is composed of environmental factors and personal factors. The environment in social e-commerce is composed of users' social media friends. If the friends forward more advertising information, users will be more likely to purchase.

- $\quad P$ is the threshold of purchasing. Only if individual $i$ 's purchase intention is greater than the purchase threshold, the purchase behavior will occur. Additionally, the concept of user loyalty (the retention rate after APP(Application) is activated for one month) mentioned in the "Meilishuo Case Study Report" published by iResearch in 2013 has set users' purchase threshold. The report points out that Beauty's user loyalty is $51 \%$, so a purchase threshold 0.5 is set in our model.

- $\quad p c$ is the group purchase rate. That is, the ratio of the number of buyers to the total number of e-commerce users in the online shopping community.

\subsection{Game Setting}

The prisoner's dilemma model is used to describe the game between each user and their friends, and the payoff matrix is described as $M$ [64]:

$$
M=\left(\begin{array}{cc}
b-c & -c \\
b & 0
\end{array}\right)
$$

The two parameters of the matrix, $b$ and $c$ are usually simplified to describe the interactions payoff among participants in the Prisoners' dilemma, where parameter $b$ represents the benefits of cooperative behavior, and parameter $c$ represents the costs of cooperative behavior $[65,66]$, usually $b>c$. Zhou et al. confirmed through a large amount of actual data that a price discount would contribute to increasing consumers' interest in the promotional advertisement [34]. Therefore, the benefits brought by forwarding information are affected by the price discounts on the advertising information. The relationship between price discount and benefits is as follows:

$$
b=b_{0}+k d
$$

In the equation, $b_{0}$ is the benefit not affected by the discount, which may be related to the quality of the advertisement. $d$ is the price discount, that is, the percentage of the reduced price in the total 
price of goods. $k$ is the influence degree of the price discount on users' forwarding, which may be affected by brand and commodity type.

\subsection{Updating Mechanism}

The model adopts an asynchronous update mechanism [67]. At time $t$, an individual is selected at random, and their strategy is adjusted according to probability q (as Equation (4)); otherwise, their partnership is adjusted.

$$
\begin{gathered}
q=\frac{1}{(1+w)} \\
W=\frac{\tau_{e}}{\tau_{p}}
\end{gathered}
$$

$w$ (as Equation (5)) is the ratio between time scale of strategy updating $\tau_{e}$ and time scale of partnership adjustment $\tau_{p}$ [68]. $w$ represents the level of community activity. $w$ will change positively with the frequency of the users changing their social relations and communicating.

\subsubsection{Strategy Updating}

When an individual changes their information strategy, individual $i$ selects individual $j$ (as Equation (6)), who has the highest utility, from their OUT-neighbors, and imitates j's strategy.

$$
j=\arg \max _{l \in N_{i}^{o}}\left\{u_{l}>u_{i}\right\}
$$

The imitation process can be described by the Fermi rule [69]:

$$
w\left(s_{i} \leftarrow s_{j}\right)=\frac{1}{1+\exp \left[\beta\left(u_{j}-u_{i}\right)\right]}
$$

where $S_{i}$ and $S_{j}$ are strategies adopted by agents $i$ and $j, u_{i}$ and $u_{j}$ are utilities of individual $i$ and $j$, respectively. $\beta$ represents the extent of imitation noise.

\subsubsection{Partnership Adjusting}

Individual $i$ will change the existing friendship relationship according to the reputation, disconnect the existing friendship from the users with lower-reputation neighbors, and establish a new friendship with a higher-reputation individual. Individual $i$ 's reputation is updated as follows:

$$
\left\{\begin{array}{l}
R_{i}(t)=\sigma R_{i}(t-1)+\Delta R_{i}(t) \\
\Delta R_{i}(t)=\sin \left(\frac{\pi \cdot n_{i}^{C}}{2 \cdot d_{i}}\right)
\end{array}\right.
$$

where $n_{i}{ }^{C}$ is the number of cooperative friends among the individual $i$ 's neighbors, and the change rate of reputation is described by a sine function.

Since social networks have direction, when individuals adjust their friendship, they can only cancel the connection with the individuals they follow. Individual $i$ disconnects with user $j$ with probability $p_{s}$ from the neighbor, and $j$ is as follows:

$$
j=\arg \min _{l \in N_{i}^{O}}\left\{R_{l}(t)<R_{i}(t)\right\}
$$

When establishing a new social relationship, individual $i$ chooses the individual with the highest reputation among their IN-neighbor and OUT-neighbor's OUT-neighbor $k$. Then, individual $i$ establishes the friendship with them with probability $p_{r}$, and $k$ is as follows:

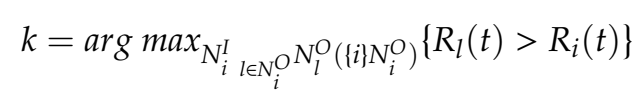


Otherwise, individual $i$ randomly selects individual $k^{\prime}$ as their new friend with probability $1-p_{r}$ from their IN-neighbor and OUT-neighbor's OUT-neighbor.

\subsubsection{Purchase Intention Updating}

Purchase intention is influenced by environmental factors and personal factors. The environment in social media is the viewpoint of network friends. Personal factors are determined by consumers' perceived value. This paper mainly concerns the part of the perceived value affected by price discounts. Individual $i$ 's purchase intention $B_{i}(i)$ is updated as follows:

$$
B_{i}(i)=\lambda_{1}\left[\omega_{1} * \theta_{1} * e^{\frac{w}{1+w} * p_{r}} * \frac{m_{i 1}}{k_{i 1}}(t)+\omega_{2} * \theta_{2} * e^{\frac{w}{1+w} * p_{r}} * \frac{m_{i 2}}{k_{i 2}}(t)\right]+\lambda_{2} f(d)
$$

where $\lambda_{1}$ and $\lambda_{2}$ are the influence degree of environmental factors and personal factors on purchase behavior. $\omega_{1}$ represents the influence degree of individual $i$ 's OUT-neighbors on the individual $i$ participating in interactions, while $\omega_{2}$ represents the influence degree of the OUT-neighbors' OUT-neighbors participating in interactions on the individual $i . \theta_{1}$ is the probability that individual $i$ finds their OUT-neighbor forwarding the information. $\theta_{2}$ is the probability that individual $i$ finds their OUT-neighbor's OUT-neighbor forwarding the information.

$m_{i 1}$ is the out-degree of individual $i . k_{i 1}$ is the number of individual $i$ 's OUT-neighbors participating in interactions. $m_{i 2}$ is the out-degree of individual $i$ 's OUT-neighbors. $k_{i 2}$ is the number of individual $i$ 's OUT-neighbors' OUT-neighbors participating in interactions. $t$ means at time $t . f(d)$ is the function that the individual's perceived value changes with $d$.

\subsection{Simulation Tool}

In this study, the Igraph processing package compiled in the $C$ language is applied to run on the computer terminal. Igraph is a free complex network (graphs) processing packet that can handle a network of millions of nodes (depending on machine memory). Igraph offers $\mathrm{R}$ and $\mathrm{C}$ packages, along with Python and Ruby extensions, and includes features such as:

- $\quad$ network visualization;

- traditional graph theory algorithm: minimum spanning tree, network flow;

- complex network processing algorithm: random network model, network processing (K-cores, PageRank, Betweenness, motifs), community discovery algorithm.

When the network scale expands rapidly, the situation will become complicated, and the cost and overhead of processing network structure will also increase accordingly. Many functions of Igraph are developed with the $C$ language, with high computing efficiency, which is very suitable for solving large-scale complex network problems. For this study, Igraph can be used to generate a directed graph with hundreds of nodes, and the nodes can be filtered and traversed according to model requirements to increase or decrease edges. The data will evolve with the change of parameters until the steady state is reached. In this research, the simulation data is huge and the network structure is complex, so Igraph can be used to simulate the real scene with high efficiency and more precision.

\section{Numerical Results}

In the model simulation, a network is established with uniformity of degree $K=4$ and the total number of social e-commerce community $N=500$. At the initial stage, product promotional information is put into the social media community, and some "active users" participate in information dissemination. In the simulation, the important parameter variables established are $d, p_{r}$, and $w$. This paper mainly analyzes the influence of promotional information on the group purchase rate $p c$ with the change of the above parameters. $d$ is the price discount, the range of $d$ is 0 to 1 , and the sampling interval is 0.05 . When $d=0$, it means that there is no price discount. As $d$ approaches 1 , the price discount gradually increases. $p_{r}$ is the reputation in the whole network, while $w$ is the frequency of 
partnership updates. The sampling interval of $p_{r}$ and $w$ is 0.1 , and the range is $0-1$. When $p_{r}=0$, the individual randomly selects neighbors without regard to reputation. When $p_{r}=1$, individuals follow the principle of maximum reputation when choosing neighbors. $w$ is positively correlated with the frequency of partnership updates. When $w=0$, the individual only updates the behavioral strategies but not the partnership. When $w=1$, individuals update their behavioral strategies and partnerships equally.

When the proportion of cooperation does not fluctuate significantly, the evolution is relatively stable, otherwise it runs $2 \times 10^{5}$ Monte Carlo (MC) time steps. After that, it evolves another $10^{3}$ cycles. Take the average of these $10^{3}$ cycles for the purchase rate of goods. Record the above process as a simulation process. On this basis, the results of the model are averaged 20 times in an independent simulation process.

The main fixed parameters in the model in this paper are as follows:

- Simulation noise $\beta=0.03$, disconnecting probability $p_{s}=0.01$, reputation memory decay factor $\sigma=1$.

- It is assumed that personal factors and environmental factors have the same weight on individuals, that is, $\lambda_{1}=\lambda_{2}=0.5$.

- Consumers measure the attractiveness of promotional information by the extent of price concessions. Many studies have confirmed the impact of price discounts on consumers' price perception. This effect is not simply linear. Zhao (2015) confirmed this rule with a large number of empirical studies [70]. Here, formula (12) is used to fit the relationship between daily necessities' price discount and perceived value.

$$
f=-0.59 d^{2}+1.3 d
$$

- According to Meilishuo's (a famous social e-commerce platform in China) website, $69.5 \%$ of the reasons for recommending Meilishuo's website to others are "providing shopping guidance". Therefore, set $\omega_{1}=0.7, \omega_{2}=0.3$.

- Individuals discover their neighbors' forwarding messages with equal probability, that is, $\theta_{1}=\theta_{2}=0.5$.

- Average initial purchase threshold $\mu=0.5$, randomly distributed between 0 and 1 .

This study uses Matlab to process data and draw images. Simulation data are shown in Figure 3, which illustrates the temperature graph of $p c$ changing with $d$ and $w$ when $p_{r}$ is between 0 and 1 . Abscissa stands for $w$ and ordinate for $d$. The color represents the value of the $p c$. Dark red indicates a high purchase rate, while blue means low.
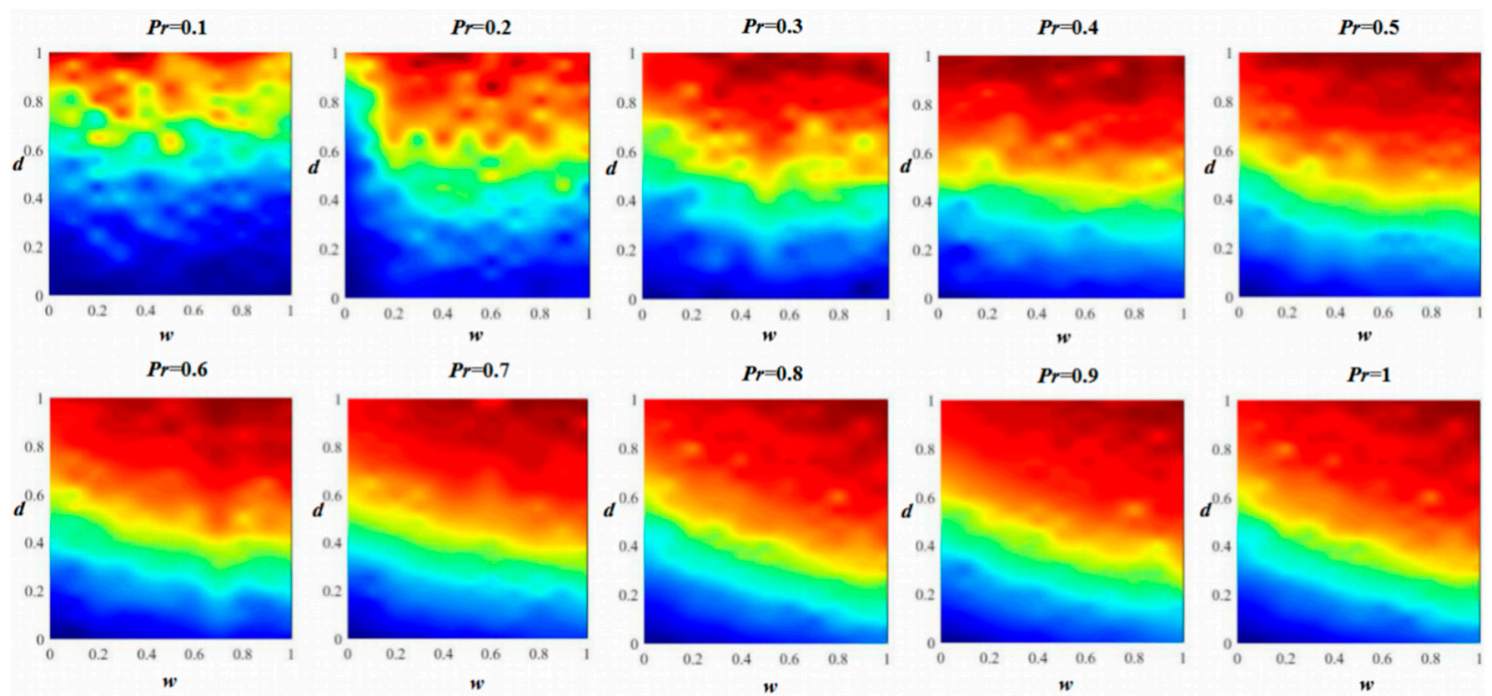

Figure 3. When $0 \leq p_{r} \leq 1$, the influence of $w$ and $d$ on $p c$. 
When $p_{r} \leq 0.4$, representing a low-reputation environment, the increase of $d$ significantly increases $p c$, while $w$ does not affect $p c$. After $p_{r}>0.4$, representing a high-reputation environment, the increase of $w$ will lead to the increase of $p c$. The effect of $w$ on $p c$ will become more significant with the increase of $p_{r}$. In other words, frequent communication can increase the purchase rate of consumers in high-reputation e-commerce platforms. Merchants can give additional rewards to users who forward information in order to stimulate information dissemination. However, for individuals in low-reputation e-commerce platforms, frequent communication has little promoting effect, and merchants can use greater discounts to stimulate their purchase desire. For the e-commerce platform, in order to gain more sales, it is necessary to improve the regulatory mechanism to improve its reputation.

There is an "inflection point" for $d$ in each $w$ state. When $d$ reaches the "inflection point", the growth rate of $p c$ drops sharply. As shown in Figure $4 \mathrm{~b}$, when $w=1$, the $p c$ growth trend gradually slows down after $d$ reaches 0.45 . When $w=0.1$, the $p c$ growth trend gradually slows down after $d$ reaches 0.6 . So, $\mathrm{A}$ is the inflection point when $p_{r}=1, w=1$. $\mathrm{B}$ is the inflection point when $p_{r}=1, w=0.1$.

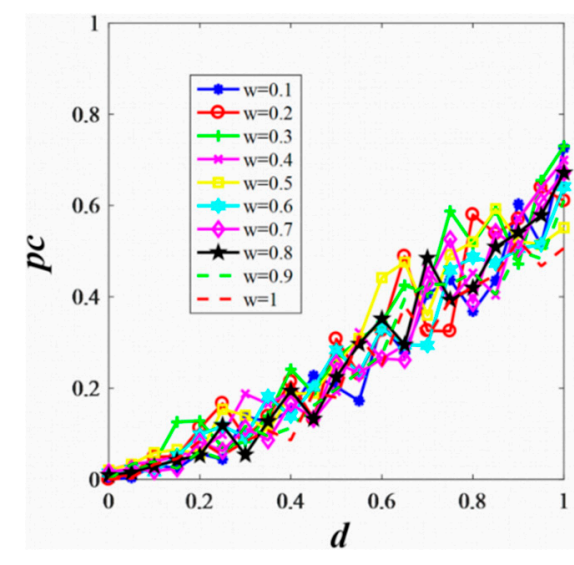

(a)

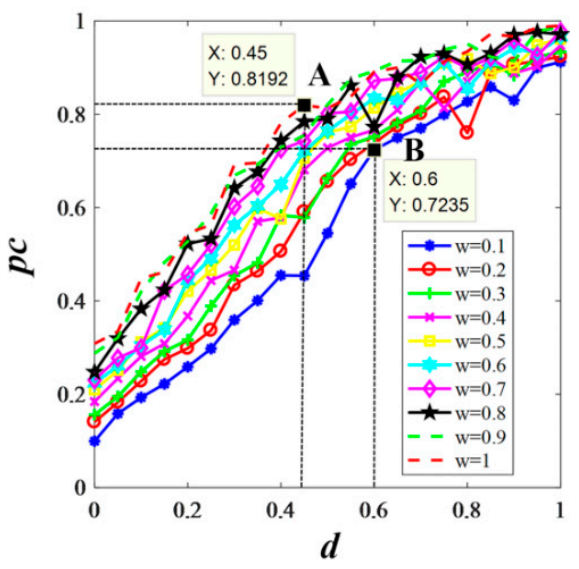

(b)

Figure 4. The influence of $d$ on $p c$ under different $w$ values: (a) given $p_{r}=0.1,0 \leq d \leq 1$; (b) given $p_{r}=1$, $0 \leq d \leq 1$.

$d=0.6$ and $d=0.45$ are two important values. Table 3 shows the influence of inflection point $d$ value on $p c$, when $p_{r}>0.4,0 \leq w \leq 1$. When $d$ is higher than the inflection point, the average growth rate of $p c$ is significantly higher than that when $d$ is lower than the inflection point. $p c$ can be maintained at a relatively stable high level if $d$ reaches 0.6 when $p_{r}>0.4$. As $w$ increases, the value of $d$ at the inflection point changes, the minimum value of $d$ at the inflection point is 0.45 . That is, in high-reputation e-commerce platforms, merchants can achieve a high group purchase rate by offering discounts only ranging from $45 \%$ to $60 \%$.

Table 3. The influence of the value of inflection point $d$ on $p c$, given $p_{r}>0.4,0 \leq w \leq 1$.

\begin{tabular}{|c|c|c|c|c|c|c|c|c|c|c|c|}
\hline \multirow{2}{*}{$p_{r}$} & & \multicolumn{10}{|c|}{$w$} \\
\hline & & 0.1 & 0.2 & 0.3 & 0.4 & 0.5 & 0.6 & 0.7 & 0.8 & 0.9 & 1 \\
\hline \multirow{3}{*}{0.5} & Inflection point $d$ value & 0.55 & 0.55 & 0.6 & 0.5 & 0.5 & 0.6 & 0.6 & 0.55 & 0.55 & 0.6 \\
\hline & lower ${ }^{1}$ & 0.973 & 1.026 & 1.077 & 1.044 & 1.026 & 1.006 & 1.006 & 1.058 & 1.045 & 1.03 \\
\hline & higher $^{2}$ & 0.643 & 0.552 & 0.497 & 0.546 & 0.537 & 0.402 & 0.402 & 0.344 & 0.384 & 0.299 \\
\hline \multirow{3}{*}{0.6} & Inflection point $d$ value & 0.55 & 0.55 & 0.5 & 0.55 & 0.55 & 0.6 & 0.5 & 0.45 & 0.45 & 0.45 \\
\hline & lower ${ }^{1}$ & 0.997 & 0.962 & 1.015 & 1.018 & 1.027 & 1.006 & 1.128 & 1.12 & 1.12 & 1.128 \\
\hline & higher $^{2}$ & 0.618 & 0.623 & 0.563 & 0.464 & 0.379 & 0.365 & 0.386 & 0.483 & 0.475 & 0.475 \\
\hline
\end{tabular}


Table 3. Cont.

\begin{tabular}{|c|c|c|c|c|c|c|c|c|c|c|c|}
\hline \multirow{2}{*}{$p_{r}$} & & \multicolumn{10}{|c|}{$w$} \\
\hline & & 0.1 & 0.2 & 0.3 & 0.4 & 0.5 & 0.6 & 0.7 & 0.8 & 0.9 & 1 \\
\hline \multirow{3}{*}{0.7} & Inflection point $d$ value & 0.6 & 0.6 & 0.55 & 0.5 & 0.5 & 0.5 & 0.5 & 0.5 & 0.5 & 0.45 \\
\hline & lower ${ }^{1}$ & 1.013 & 1.009 & 1.063 & 1.036 & 1.056 & 1.061 & 1.055 & 1.075 & 1.057 & 1.144 \\
\hline & higher $^{2}$ & 0.484 & 0.455 & 0.48 & 0.496 & 0.492 & 0.251 & 0.465 & 0.409 & 0.431 & 0.367 \\
\hline \multirow{3}{*}{0.8} & Inflection point $d$ value & 0.6 & 0.6 & 0.55 & 0.5 & 0.45 & 0.5 & 0.5 & 0.5 & 0.45 & 0.45 \\
\hline & lower ${ }^{1}$ & 0.991 & 1.025 & 1.028 & 1.036 & 1.049 & 1.101 & 1.074 & 1.105 & 1.073 & 1.1 \\
\hline & higher $^{2}$ & 0.544 & 0.527 & 0.463 & 0.296 & 0.387 & 0.475 & 0.403 & 0.389 & 0.381 & 0.378 \\
\hline \multirow{3}{*}{0.9} & Inflection point $d$ value & 0.6 & 0.6 & 0.55 & 0.5 & 0.45 & 0.5 & 0.5 & 0.5 & 0.45 & 0.45 \\
\hline & lower ${ }^{1}$ & 1.024 & 1.01 & 1.023 & 1.086 & 1.098 & 1.08 & 1.099 & 1.096 & 1.13 & 1.114 \\
\hline & higher $^{2}$ & 0.541 & 0.477 & 0.432 & 0.45 & 0.405 & 0.402 & 0.275 & 0.262 & 0.311 & 0.345 \\
\hline \multirow{3}{*}{1} & Inflection point $d$ value & 0.6 & 0.55 & 0.55 & 0.5 & 0.5 & 0.5 & 0.5 & 0.45 & 0.5 & 0.45 \\
\hline & lower ${ }^{1}$ & 1.04 & 0.996 & 1.015 & 1.087 & 1.103 & 1.08 & 1.143 & 1.193 & 1.065 & 1.135 \\
\hline & higher ${ }^{2}$ & 0.471 & 0.464 & 0.54 & 0.438 & 0.402 & 0.402 & 0.352 & 0.34 & 0.333 & 0.311 \\
\hline
\end{tabular}

${ }^{1}$ Lower means the average growth rate of $p c$ when $d$ is lower than the inflection point $d$ value; ${ }^{2}$ higher means the average growth rate of $p c$ when $d$ is higher than the inflection point $d$ value. Bold is necessary to highlight that the data range is between 0.45 and 0.6 .

As shown in Figure 5, when $d=0.6$, $w$ positively affects the purchase rate. When $p_{r} \leq 0.4$, the purchase rate increases significantly with the increase of $p_{r}$, and reaches a relatively stable state when $p_{r}>0.4$.

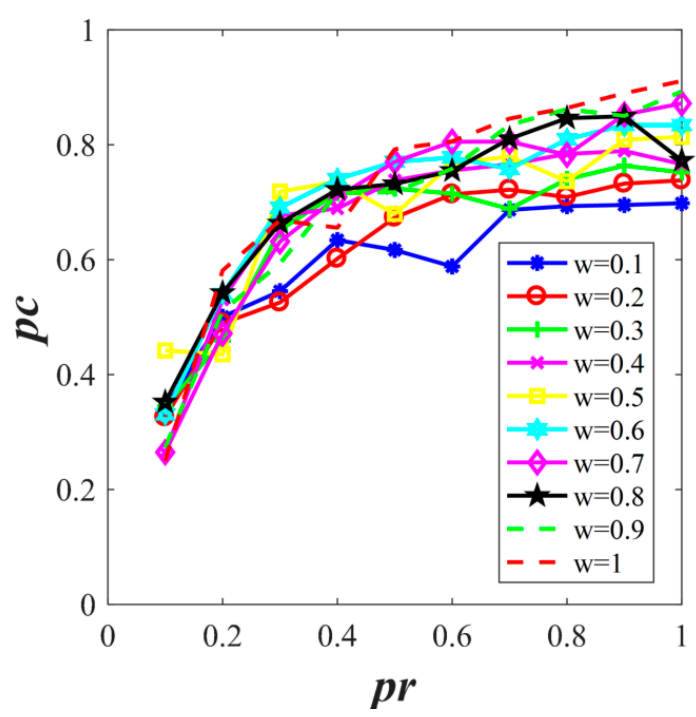

Figure 5. The influence of $p_{r}$ on $p c$, given $d=0.6,0 \leq w \leq 1$.

Figure 4a,b describe the influence of $d$ on $p c$ under different $w$ values, given $p_{r}=0.1$ and $p_{r}=1$, respectively. In Figure $4 \mathrm{a}$, when $p_{r}=0.1$, $p c$ will not change with $w$, but it will change with $d$, and the growth rate will increase gradually. Increasing $d$ will significantly improve $p c$. In Figure $4 \mathrm{~b}$, when $p_{r}=1$, $p c$ still positively changes with $d$, but the growth rate drops sharply after reaching the inflection point. A high $p c$ value can be achieved only by reaching the inflection point $d$ value. The convexity of the curve changes between different $p_{r}$ values.

The increase in $p_{r}$ has eroded consumers' preference for a high price discount. That is, in low-reputation e-commerce platforms, businesses need to give higher price discounts to stimulate the purchase. In high-reputation e-commerce platforms, a discount between $45 \%$ and $60 \%$ can increase purchase effectively.

This rule can be verified in real life. Low-reputation e-commerce platforms have relatively loose supervision on pricing and discount of merchants, which will lead to overpriced and disorderly pricing. Therefore, the complaint rate of the e-commerce platform is taken as the measurement 
standard of reputation. The complaint rate was calculated by dividing the number of complaints on the "cluster complaint" website by the total number of active users on the platform. We show the complaint rate of the 13 most popular social e-commerce platforms in China (See Table 4). If the number of complaints per million users exceeds 1000, we call it a low-reputation e-commerce platform; if the number is below 1000, it is a high-reputation e-commerce platform.

Table 4. Reputation rankings for popular e-commerce platforms in China.

\begin{tabular}{cccccc}
\hline Social E-Commerce & $\begin{array}{c}\text { Number of } \\
\text { Platform }\end{array}$ & $\begin{array}{c}\text { Quarterly } \\
\text { Active Users }\end{array}$ & $\begin{array}{c}\text { Number of Complaints per } \\
\text { Million People }\end{array}$ & Reputation \\
\hline 1 & Vipshop & 143 & 53.682 & 266.38 & High \\
2 & Jumei & 15 & 5.1642 & 290.461 & High \\
3 & Mogujie & 38 & 11.051 & 343.835 & High \\
4 & Taobao & 1504 & 396.102 & 379.7 & High \\
5 & Little Red Book & 63 & 11.643 & 541.056 & High \\
6 & Jingdong Mall & 1508 & 192.199 & 784.601 & High \\
7 & Netease Yanxuan & 14 & 1.759 & 795.907 & High \\
8 & Alibaba & 117 & 12.542 & 932.828 & High \\
9 & Microshop & 51 & 4.989 & 1022.126 & Low \\
10 & Tmall & 697 & 47.547 & 1465.912 & Low \\
11 & Pinduoduo & 3468 & 222.701 & 1557.241 & Low \\
12 & Yangmatou & 14 & 0.687 & 2036.364 & Low \\
13 & Suning & 1525 & 41.367 & 3686.433 & Low \\
\hline
\end{tabular}

The data are from the second quarter of 2020. Quarterly active users are measured in millions.

We take two e-commerce platforms as a simple example. Pinduoduo, an e-commerce platform of low reputation, sells more than one million units of hot style, mainly low-priced commodities. Most people there pay little attention to word of mouth and the brand, mainly because they are attracted by the low price. Only by sharing a shopping link with your social media friends can you get a discount price. Jingdong, an e-commerce platform of high reputation, insists on authentic goods and guarantees the quality of goods. Jingdong also uses social media for publicity, by setting a Jingdong shopping portal link on the WeChat (the most widely used social media in China) interface. Both Pinduoduo and Jingdong are promoting the same body wash (See Figure 6). We can see that the original price of the goods is 68 yuan and the price on Pinduoduo is 16.9 yuan, which is equivalent to a discount of about $68 \%$. The price on Jingdong is 29 yuan, equivalent to a $57 \%$ discount. At the same time, the ranking list of shower gel sales on the two shopping platforms is presented (See Figure 7), which is updated in real time based on the recent sales volume and total transaction volume.
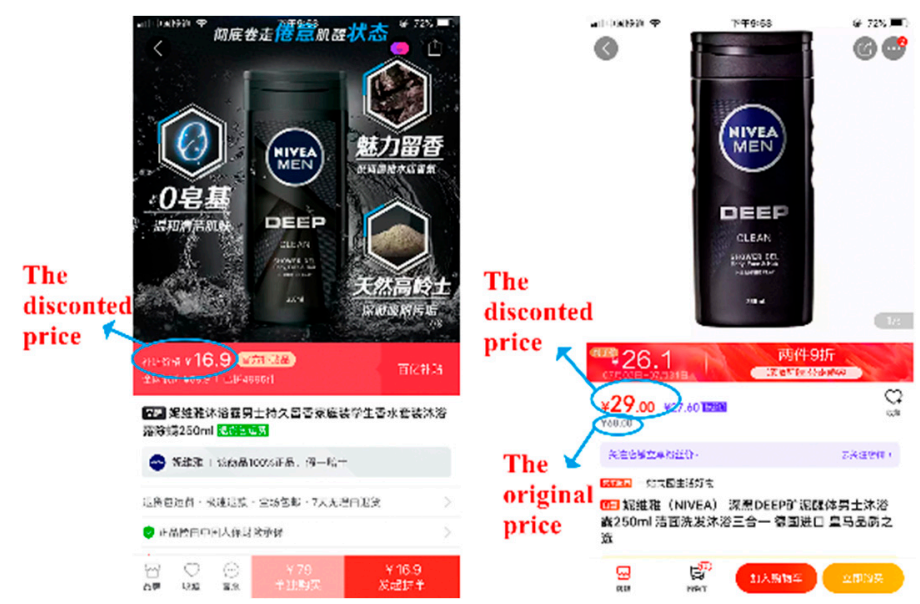

Figure 6. Mobile app window from Pinduoduo (left) and Jingdong (right) displaying the shopping interface. 


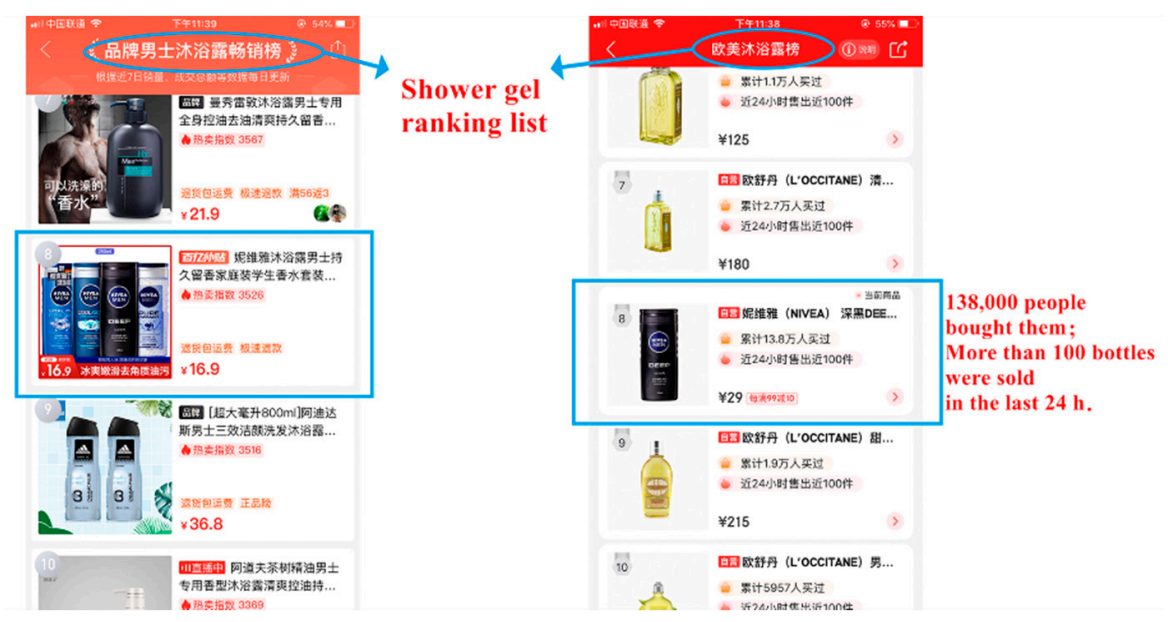

Figure 7. Mobile app window from Pinduoduo (left) and Jingdong (right) displaying the shower gel ranking list.

As shown in Figure 7, both of the two products are listed on their respective platforms, and both rank 8th, indicating a high level of purchase. This is consistent with the law obtained in this article. For merchants, selling goods on e-commerce platforms with a low reputation will cost them more, while selling goods on platforms with a high reputation will save costs. Then all the businesses should work together, reasonable pricing, and improve their quality to create a high-reputation environment, in order to sustainable development.

\section{Discussion}

Previous studies [9-11,26] have pointed out that the combination of social media and e-commerce can be more efficient, which is a new trend in the e-commerce industry in the future. Under the current COVID-19 global epidemic, the contactless shopping process and the continued global economic downturn have made the trend of social e-commerce more obvious and inevitable. The social function has a positive effect on users' perception, thus improving their purchase intention [71,72]. In this study, we explore the optimal implementation strategy of discounts in social e-commerce from a quantitative perspective. Discount is one of the effective means for merchants to promote sales in traditional shopping. This effect will be amplified under the diffusion effect of social media. This paper first incorporates the discount factor into the specific formula, so that the purchase rate can be simulated and calculated. The reputation of e-commerce platforms is also taken into account as an important factor for sustainable development. It further establishes the linking between the two platforms to better combine the purchase behavior with information transmission behavior.

In this paper, the optimal discount range under different conditions is obtained by simulation of the evolution game in the virtual community. In low-reputation e-commerce platforms, the price discount is the main motivation to increase the purchase, while strengthening the interaction between users in social media has little effect. Through the diffusion effect of social media, the merchant should set a discount of more than $60 \%$ to achieve a high purchase rate. However, consumers' preference for the high discount is weakened by the increase in e-commerce platforms' reputation. In high-reputation e-commerce platforms, merchants only need to offer a discount of $45 \%$ to $60 \%$ to achieve a high purchase rate, and enhancing the interaction between users also has a positive effect. Merchants and platforms can launch interactive advertisements and activities on social platforms to stimulate consumers' desire to share.

Finally, a practical case is given to verify the validity of the evolutionary game model. The same body wash is sold at a $68 \%$ discount in Pinduoduo, a low-reputation e-commerce platform, and at a $57 \%$ discount in Jingdong, a high-reputation e-commerce platform, when both platforms adopt social platform promotion strategies. In addition, the product has reached a high purchase rate on both 
platforms. The simulation of daily necessities in social e-commerce based on the above rules accords with the reality of mainstream platforms. In low-reputation platforms, e-commerce merchants need to offer low prices with small profit margins, while in high-reputation platforms, the profit margins are larger. High-quality businesses naturally tend to sell on a high-reputation platform. Under the normal market rules, it is difficult for law-abiding merchants to develop sustainably in low-reputation platforms. In the long run, low-reputation platforms struggle to attract high-quality merchants and consumers. This forces low-reputation platforms to enhance their reputation or be eliminated from the market. These rules are of guiding significance for merchants to formulate reasonable price discount strategies and the overall industry ecology can be purified to ensure sustainable development.

\section{Conclusions}

With the background of the global economic downturn caused by COVID-19, this paper establishes an evolutionary game model of social media promotion strategies in e-commerce, investigates the dynamically changing process of price discount information transmission through social media, and further explores its impact on purchase behavior.

\subsection{Theoretical Implications}

This study advances knowledge about the sustainable development of social e-commerce. Common awareness of discount strategy has gradually changed from increasing the short-term profits of enterprises to making enterprises develop sustainability in the long run. Many scholars believe that discounts do not necessarily positively affect consumers' purchase intention. Raghubir showed that increasing discounts does not always improve transaction evaluation or purchase intention, and may even result in a decline in corporate profits [73]. How to optimize discount value is an important issue in promotion decision. Although there are more and more studies on promotion strategies in e-commerce, most of them focus on a specific scenario or product and collect actual data to verify the viewpoints. However, such research lacks the exploration of rules and mechanisms and do not take into account the effect of social media. This paper makes up for the lack of knowledge in this area.

An important contribution of this research is putting the price discount factor as a measurable variable in the formula, making it possible to obtain the optimal discount value under specific parameters. Discount has a moderating effect on consumption behavior. An excessively low price may reduce purchase intention or weaken the efficiency of promotion. In the strategy of using social media for publicity, discount plays a significant role in word-of-mouth marketing. Previous studies have characterized these effects, but lack a discussion and simulation of the optimal discount range [32,74,75].

Another key contribution is establishing a link between information dissemination and purchasing behavior. Shopping information in social networks not only influences individual purchases, but also influences their online friends through information dissemination, which finally spreads to the whole shopping network. With establishing a social evolution game model of social e-commerce, this research studies the rules of promotion information transmission in social e-commerce and its influencing mechanism on consumer behavior. The interaction and fusion of two independent systems widen the ideas of social network and consumer behavior.

\subsection{Practical Implications}

This study takes full advantage of the immediacy and extensiveness of social media and the navigability of consumer networks. In online consumption, user consumption behavior is easily affected by factors such as recent sales volume, buyer evaluation, and price of goods. Through group buying, the promotion will be able to guide online consumption behavior. At the same time, the recommendation of socialized shopping information will effectively influence consumption behavior. With the development of social information networks, on platforms such as instant messaging apps, microblogs, and group-buying forums, a large amount of new online consumption information is released at any time and spread 
rapidly and widely through various channels, enabling more online consumers to make choices based on promotional information.

On one hand, this enables e-commerce businesses to set reasonable discount ranges according to different conditions, achieve a high purchase rate while saving promotional costs, and ensure the optimal profit of enterprises. In addition to discounts, e-commerce companies can increase the frequency of communication between consumers. They can set strategies such as sharing information with friends to get discounts or posting high-quality advertising content on social platforms to stimulate consumers' desire to discuss and share.

On the other hand, results on the reputation environment of e-commerce platforms enable them to not only focus on short-term profits, but also consider long-term reputation, to strengthen their supervision and enable all e-commerce businesses to achieve sustainable long-term development. The platform can stop in a timely fashion and warn merchants to reduce unreasonable pricing behavior (disorderly pricing and excessively high pricing) in the market order. Establishing credit points is useful for the platform to maintain the overall reputation environment. If the points are too low, merchants will not be able to sell goods on the platform. High-quality goods placed on low-reputation shopping websites are likely to cause slow sales, which makes low-reputation shopping platforms unable to attract high-quality merchants in the long run, thus transforming their reputation or being eliminated by the market and fundamentally purifying the e-commerce ecology.

\subsection{Limitations and Future Research}

Due to the limitation of certain objective conditions, the research in this paper still has some deficiencies. Extracting big data from both social media and shopping sites is difficult at present. Although this paper uses a case to verify the conclusion simply, it is not based on the result of big data and may be accidental. In the future, the technology for collecting data is expected to improve.

In the model of this paper, network friends are an environmental factor that influences consumers' purchase intention. However, different social relationships have result in influence to different degrees. People tend to imitate the behavior of acquaintances rather than strangers. There may also be nodes with great influence in social networks, such as opinion leaders. They may be an authority in an industry or a star with a large following. Those nodes need to be distinguished from ordinary nodes by their level of reputation and influence. In this paper, only ordinary people in the online community are considered. In the follow-up research, relationship strength and opinion leaders can be introduced into the research model to explore the influence mechanism of different interpersonal relationships on purchase intention.

In addition, there are also emotional factors that prompt consumers to generate purchase intention, such as perceived pleasure [76]. In further research, consumers' emotional factors can be included as intermediate variables on purchase intention. At present, there are many emerging marketing models, such as live streaming platforms and famous stars selling goods, whose decision-making rules and sustainability also need to be studied in the future [77].

Author Contributions: Conceptualization: J.L.; methodology: J.L., Y.W.; software: Y.W., Z.W.; validation: J.L., Y.W., Y.H.; formal analysis: T.W.; investigation: Z.W., T.W.; writing-original draft preparation: Z.W.; writing一review and editing: J.L., Y.H. All authors have read and agreed to the published version of the manuscript.

Funding: This research was funded by BEIJING SOCIAL SCIENCE FUND, grant number 19GLB039.

Conflicts of Interest: The authors declare no conflict of interest.

\section{References}

1. Website of Central People's Government of the People's Republic of China. Available online: http: //www.gov.cn/xinwen/2020-04/18/content_5503803.htm (accessed on 30 August 2020).

2. Mangold, W.G.; Faulds, D.J. Social media: The new hybrid element of the promotion mix. Bus. Horiz. 2009, 52, 357-365. [CrossRef] 
3. Lee, S.Y.T.; Phang, C.W.D. Leveraging social media for electronic commerce in asia: Research areas and opportunities. Electron. Commer. Res. Appl. 2015, 14, 145-149. [CrossRef]

4. Brandon, V.D.H.; Lim, Y.S. On the conditional cueing of credibility heuristics: The case of online influence. Commun. Res. 2016, 43, 672-693.

5. Biucky, S.T.; Abdolvand, N.; Harandi, S.R. The effects of perceived risk on social commerce adoption based on TAM model. Int. J. Electron. Commer. Stud. 2017, 8, 173-196.

6. Kao, S.W.; Luarn, P. Topic Modeling Analysis of Social Enterprises: Twitter Evidence. Sustainability 2020, 12, 3419. [CrossRef]

7. Tsai, H.; Bagozzi, R.P. Contribution behavior in virtual communities: Cognitive, emotional, and social influences. Manag. Inf. Syst. Q. 2014, 38, 143-164. [CrossRef]

8. Sun, Y.; Wei, K.K.; Fan, C.; Lu, Y.; Gupta, S. Does social climate matter? On friendship groups in social commerce. Electron. Commer. Res. Appl. 2016, 18, 37-47. [CrossRef]

9. Bergström, T.; Bäckman, L. Marketing and PR in Social Media: How the Utilization of Instagram Builds and Maintains Customer Relationships. Bachelor's Thesis, Stockholm University, Stockholm, Sweden, June 2013. Available online: http://urn.kb.se/resolve?urn=urn:nbn:se:su:diva-90410 (accessed on 9 September 2020).

10. Bridges, E. Hedonic and utilitarian shopping goals: A decade later. J. Glob. Sch. Mark. Sci. 2018, 28, $282-290$. [CrossRef]

11. Duffett, R. The YouTube Marketing Communication Effect on Cognitive, Affective and Behavioural Attitudes among Generation Z Consumers. Sustainability 2020, 12, 5075. [CrossRef]

12. Sohu Net. Available online: https://www.sohu.com/a/342633463_135869 (accessed on 30 August 2020).

13. Baghdadi, Y. A framework for social commerce design. Inf. Syst. 2016, 60, 95-113. [CrossRef]

14. Friedrich, T. Analyzing the factors that influence consumers' adoption of social commerce-A literature review. In Proceedings of the Americas Conference on Information Systems (AMCIS), Puerto Rico, USA, 13-15 August 2015.

15. Liu, X.; Datta, A.; Rzadca, K. Trust beyond reputation: A computational trust model based on stereotypes. Electron. Commer. Res. Appl. 2013, 12, 24-39. [CrossRef]

16. Cennamo, C.; Santal, J. Platform Competition: Strategic Trade-offs in Platform Markets. Strateg. Manag. J. 2013, 34, 1331-1350. [CrossRef]

17. Wang, H.; Ko, E.; Woodside, A.; Jihye, Y. SNS marketing activities as a sustainable competitive advantage and traditional market equity. J. Bus. Res. 2020. [CrossRef]

18. Lirong, C.; Tao, J.; Wenli, L. Who should pay for online reviews? Design of an online user feedback mechanism. Electron. Commer. Res. Appl. 2017, 23, 38-44.

19. Oliveira, T.; Alhinho, M.; Rita, P.; Dhillon, G. Modelling and testing consumer trust dimensions in e-commerce. Comput. Hum. Behav. 2017, 71, 153-164. [CrossRef]

20. Weathers, D.; Sharma, S.; Wood, S.L. Effects of online communication practices on consumer perceptions of performance uncertainty for search and experience goods. J. Retail. 2007, 83, 393-401. [CrossRef]

21. Yu, J.; Wang, Y.; Jin, X.O.; Cheng, X. Social evolutionary games. In Proceedings of the 2014 5th International Conference on Game Theory for Networks, Beijing, China, 25-27 November 2014; pp. 1-5.

22. Yu, J.; Wang, Y.; Jin, X.; Li, J.; Cheng, X. Evolutionary analysis on online social networks using a social evolutionary game. In WWW'14 Companion, Proceedings of the 23rd International Conference on World Wide Web, Seoul, Korea, 7-11 April 2014; Association for Computing Machinery: New York, NY, USA, 2014; Volume 30, pp. 415-416.

23. Wang, Y.Z.; Yu, J.Y.; Qiu, W.; Shen, H.W.; Lin, C. Evolutionary game model and analysis methods for network group behavior. Chin. J. Comput. 2015, 38, 282-300.

24. Lv, J.; Wang, T.; Wang, H.; Yu, J.; Wang, Y. A SECPG model for purchase behavior analysis in social e-commerce environment. Int. J. Commun. Syst. 2020, 33, e4149. [CrossRef]

25. Huang, Z.; Benyoucef, M. From e-commerce to social commeice: A close look at design features. Electron. Commer. Res. Appl. 2013, 12, 246-259. [CrossRef]

26. Syedahmad, S.F.; Murphy, J. Social Networking as a Marketing Tool: The Case of a Small Australian Company. J. Hosp. Mark. Manag. 2010, 19, 700-716.

27. Xie, K.; Lee, Y.J. Social Media and Brand Purchase: Quantifying the Effects of Exposures to Earned and Owned Social Media Activities in a Two-Stage Decision Making Model. J. Manag. Inf. Syst. 2015, 32, $204-238$. [CrossRef] 
28. Erkan, I.; Evans, C. The influence of e-WOM in social media on consumers' purchase intentions: An extended approach to information adoption. Comput. Hum. Behav. 2016, 61, 47-55. [CrossRef]

29. Kwahk, K.Y.; Kim, B. Effects of social media on consumers' purchase decisions: Evidence from Taobao. Serv. Bus. 2017, 11, 803-829. [CrossRef]

30. Weng, M.L. Toward a Theory of Online Buyer Behavior Using Structural Equation Modeling. Math. Models Methods Appl. Sci. 2013, 7, 34-41.

31. Weng, M.L.; Ding, H.T. Consumer Acceptance and Continuance of Online Group Buying. J. Comput. Inf. Syst. 2014, 54, 87-96.

32. Nisar, T.M.; Prabhakar, G.P. What factors determine e-satisfaction and consumer spending in e-commerce retailing? J. Retail. Consum. Serv. 2017, 39, 135-144. [CrossRef]

33. Kim, N.; Kim, W. Do your social media lead you to make social deal purchases? Consumer-generated social referrals for sales via social commerce. Int. J. Inf. Manag. 2018, 39, 38-48. [CrossRef]

34. Zhou, H.; Ma, X.; Chen, X. The influence of discount ratio in Price Comparison Advertising on consumers' positive Feedback Behavior. J. Manag. 2018, 15, 410-419.

35. Estelami, H. The Effect of Price Presentation Tactics on Consumer Evaluation Effort of Multi-dimensional Prices. J. Mark. Theory Pract. 2003, 11, 1-16. [CrossRef]

36. Mariola, P.; Delgado, E. The moderating role of price consciousness on the effectiveness of price discounts and premium promotions. J. Prod. Brand Manag. 2009, 18, 306-312.

37. Teng, L. A comparison of two types of price discounts in shifting consumers' attitudes and purchase intentions. J. Bus. Res. 2009, 62, 14-21. [CrossRef]

38. Gupta, S. Impact of sales Promotions on When, What, and How Much to Buy. J. Mark. 1988, 25, 342-355. [CrossRef]

39. Chen, Y.; Cheng, R. Single Discount or Multiple Discounts: Effects of Price Promotion Framing Messages on Online Consumer Purchase Intention. Int. J. Technol. Hum. Interact. 2019, 15, 1-14. [CrossRef]

40. Corso, K.B.; Löbler, M.L. Understanding the subject's behavior in the interaction with a decision support system under time pressure and missing information. J. Inf. Syst. Technol. Manag. JISTEM 2011, 8, 121-152.

41. Francesca, G.; Alessandro, P. Emotional Text Mining: Customer profiling in brand management. Int. J. Inf. Manag. 2019, 11, 116-132.

42. Huiling, H.; Stephanie, Q.; Liu, J.K.; Milos, B. Consumer Responses to Scarcity Appeals in Online Booking. Ann. Tour. Res. 2018, 14, 124-147.

43. Hélène, C.; Hannele, K.R. Managing the transformation of the global commons into luxuries for all. J. Bus. Res. 2016, 16, 109-118.

44. Khouja, M.; Liu, X. A retailer's decision to join a promotional event of an e-commerce platform. Int. J. Electron. Commer. 2020, 24, 184-210. [CrossRef]

45. Gong, H.; Huang, J.; Goh, K.H. The Illusion of Double-Discount: Using Reference Points in Promotion Framing. J. Consum. Psychol. 2019, 29, 483-491. [CrossRef]

46. Bearden, W.O.; Hardesty, D.M. Consumer evaluations of different promotion types and price presentations: The moderating role of promotional benefit level. J. Retail. 2003, 79, 17-25.

47. Sheehan, D.; Hardesty, D.M.; Ziegler, A.H.; Chen, H. Consumer reactions to price discounts across online shopping experiences. J. Retail. Consum. Serv. 2019, 51, 129-138. [CrossRef]

48. Carlson, J.R.; Kukar, K.M. Investigating discounting of discounts in an online context: The mediating effect of discount credibility and moderating effect of online daily deal promotions. J. Retail. Consum. Serv. 2018, 41, 153-160. [CrossRef]

49. Farzin, M.; Fattahi, M. eWOM through social networking sites and impact on purchase intention and brand image in Iran. J. Adv. Manag. Res. 2018, 15, 161-183. [CrossRef]

50. Daft, R.L.; Lengel, R.H. Information richness: A new approach to managerial behavior and organizational design. Res. Organ. Behav. 1984, 6, 191-233.

51. Day, D.; Gan, B.; Gendall, P.; Esslemont, D. Predicting purchase behaviour. Mark. Bull. 1991, 2, $18-30$.

52. Kim, D.J.; Ferrin, D.L.; Rao, H.R. Trust and satisfaction, two stepping stones for successful e-commerce relationships: A longitudinal exploration. Inf. Syst. Res. 2009, 20, 237-257. [CrossRef]

53. Qiu, W.; Wang, Y.; Yu, J. A game theoretical model of information dissemination in social network. In Proceedings of the IEEE International Conference on Complex Systems, Agadir, Morocco, 5-6 November 2012; pp. 1-6. 
54. Li, B.; Li, H.; Sun, Q.; Chen, X. Evolutionary game analysis of online collective behaviour with the introduction of the degree of psychological identity. Behav. Inf. Technol. 2020, 11,1-11.

55. Lu, Y.; Wang, Y.; Yu, J.; Li, J.; Liu, L. Mechanism Analysis of Competitive Information Synchronous Dissemination in Social Networks. In Web Technologies and Applications. APWeb 2016. Lecture Notes in Computer Science; Li, F., Shim, K., Zheng, K., Liu, G., Eds.; Springer: Cham, Switzerland, 2016; Volume 9931. [CrossRef]

56. Yu, J.; Lv, J.; Wang, Y.; Li, J. Mechanism analysis of competitive information asynchronous dissemination on social networks. Int. J. Mod. Phys. C 2019, 30, 282-416. [CrossRef]

57. Akar, E.; Dalgic, T. Understanding online consumers' purchase intentions: A contribution from social network theory. Behav. Inf. Technol. 2018, 37, 1-15. [CrossRef]

58. Ajzen, I.; Fishbein, M. The prediction of behavior from attitudinal and normative variables. J. Exp. Soc. Psychol. 1970, 6, 466-487. [CrossRef]

59. Armstrong, J.S.; Morwitz, V.G.; Kumar, V. Sales forecasts for existing consumer products and services: Do purchase intentions contribute to accuracy? Int. J. Forecast. 2000, 16, 383-397. [CrossRef]

60. Lu, H.; Hsiao, K. The influence of extro/introversion on the intention to pay for social networking sites. Inf. Manag. 2010, 47, 150-157. [CrossRef]

61. Fu, G.Q. Consumer Behavior, 3rd ed.; China Higher Education Press: Beijing, China, 2015; pp. 19-23.

62. Zeithaml, V.A. Consumer Perceptions of Price, Quality, and Value: A Means-End Model and Synthesis of Evidence. J. Mark. 1988, 52, 2-22. [CrossRef]

63. Fraccastero, K.; Burton, S.; Biswas, A. Effective use of advertisements promoting sale prices. J. Consum. Mark. 1993, 10, 61-70. [CrossRef]

64. Yang, Z. Evolutionary Dynamics of Game and Cooperation in Complex Networks; Xidian University: Xi'an, China, 2014.

65. Axelrod, R.; Hamilton, W. The evolution of cooperation. Science 1981, 211, 1390-1396. [CrossRef]

66. Hamilton, W.D. The genetical evolution of social behavior. II. J. Theor. Biol. 1964, 7, 17-52. [CrossRef]

67. Fu, F.; Hauert, C.; Nowak, M.A.; Wang, L. Reputation-based partner choice promotes cooperation in social networks. Phys. Rev. E 2008, 78, 026117. [CrossRef]

68. Santos, F.C.; Pacheco, J.M.; Lenaerts, T. Cooperation Prevails When Individuals Adjust Their Social Ties. PLoS Comput. Biol. 2006, 2, e140. [CrossRef]

69. Szabo, G.; Toke, C. Evolutionary prisoner's dilemma game on a square lattice. Phys. Rev. E 1998, 58, 69-73. [CrossRef]

70. Zhao, Y.D. Empirical Research on the Influence of Different Description Methods of Price Discount on Consumers' Purchase Intention. Master's Thesis, Southwest Jiaotong University, Chengdu, China, 2015. Available online: http://cdmd.cnki.com.cn/Article/CDMD-10613-1015338940.htm (accessed on 9 September 2020).

71. Hu, X.; Huang, Q.; Zhong, X.; Davison, R.M.; Zhao, D. The influence of peer characteristics and technical features of a social shopping website on a consumer's purchase intention. Int. J. Inf. Manag. 2016, 36, 1218-1230. [CrossRef]

72. Lin, J.; Luo, Z.; Cheng, X.; Li, L. Understanding the interplay of social commerce affordances and swift guanxi: An empirical study. Inf. Manag. 2019, 56, 213-224. [CrossRef]

73. Raghubir, P. Coupons in context: Discounting prices or decreasing profits. J. Retail. 2004, 80, 1-12. [CrossRef]

74. Ba, S.; Pavlou, P.A. Evidence of the effect of trust building technology in electronic markets: Price premiums and buyer behavior. Manag. Inf. Syst. Q. 2002, 26, 243-268. [CrossRef]

75. Arndt, J. Role of Product-Related Conversations in the Diffusion of a New Product. J. Mark. Res. 1967, 4, 291-295. [CrossRef]

76. Koshksaray, A.A.; Nabizadeh, E. Internet Advertising Pleasure and Purchase Intention. Int. J. Innov. Digit. Econ. 2018, 8, 30-47. [CrossRef]

77. Su, Q.; Zhou, F.; Wu, Y.J. Using Virtual Gifts on Live Streaming Platforms as a Sustainable Strategy to Stimulate Consumers' Green Purchase Intention. Sustainability 2020, 12, 3783. [CrossRef]

(C) 2020 by the authors. Licensee MDPI, Basel, Switzerland. This article is an open access article distributed under the terms and conditions of the Creative Commons Attribution (CC BY) license (http://creativecommons.org/licenses/by/4.0/). 